\title{
Púrpura, todo un reto diagnóstico en la consulta de Atención Primaria: a propósito de un caso
}

\author{
B. Aguado Martínez, S. TojeIRo LORENTE ${ }^{1}$ \\ Residente de Medicina Familiar y Comunitałk édico Especialista en Medicina \\ Familiar y Comunitaria. Centro de Salud San Fernando. Móstoles. Madrid.
}

\section{RESUMEN}

El hallazgo de lesiones papulares, eritematosas, que no desaparecen a la vitropresión (púrpura) lo calizadas en miembros inferiores en un contexto de vagos síntomas sistémicos, nos hace poner en mar cha todas las herramientas disponibles, en una consulta de demanda de 8 minutos, dirigidas a des cartar aquella etiología que precise un tratamiento urgente en medio hospitalario. Una anamnesis di rigida, exploración física y una petición urgente de plaquetas, tiempo de sangría y biopsia mediante la técnica de escisión cilíndrica (punch), bastarán para ese fin.

En este artículo presentamos un caso de lesiones purpúricas palpables en un paciente de riesgo.

Palabras clave: Púrpura palpable. Vasculitis leucocitoclástica. Schönlein-Henoch. Norfloxacino.
Purpura, a challenging diagnose for the family physician: a case report

\begin{abstract}
The finding of papule and red injuries located in legs which do not disappear when pressure is ap plied to them (purpura) together with other vague and systemic symptoms must trigger our medical knowledge and clinic resources in order to discard those urgent etiologyies from the ones that can be handled by our own resources, taking into account the few minutes available for every patient at the Primary Health Care clinic.

A well directed anamnesis, a physical explora tion and an urgent request for a platelet count, coagulation test and skin biopsy (punch) will fulfil this purpose.

This document contains information about a case of "palpable purpura" injury in a high risk patient.
\end{abstract}

Key words: Palpable purpura. Leukocytoclastic vasculitis. Schönlein-Henoch. Norfloxacino.

\section{INTRODUCCIÓN}

La lesión de características compatibles con púrpura constituye una causa, poco habitual, de consulta en Atención Primaria ${ }^{1}$. La objetivación de una lesión de morfología máculo-pápular, de color rojizo que no desaparece a la vitropresión, debe poner en marcha un algoritmo decisional sencillo que nos permita la orientación diagnóstica. La morfología de la lesión servirá como punto de partida: lesión macular, púrpura no palpable, orientará a etiología no vascular (alteración de plaquetas, o de la coagulación), lesión papular, púrpura palpable, orientará, a patología vascular (vasculitis). Una anamnesis

Recepción: 12-12-01

Aceptación: 24-11-02 
dirigida, explorar la lesión, y tener la posibilidad de pedir un hemograma y pruebas de coagulación, así como realizar una toma de biopsia con escisión cilíndrica (punch), bastará para una primera aproximación diagnóstica en nuestra consulta. A continuación se describe la actuación lle vada a cabo con un paciente portador de lesiones purpúricas.

\section{CASO CLÍNICO}

Paciente de 65 años con antecedentes personales de cardiopatía isquémica estable y fibrilación auricular no valvular de 2 meses de evolución, en tratamiento con acenocumarol (Sintrom $\left.{ }^{\circledR}\right)$. Acude a consulta de demanda del centro de salud por un cuadro de seis a siete días de evolución consistente en dolor testicular sin clínica genitourinaria, precedido de artromialgias y distermia. Es diagnosticado de orquitis de probable etiología infecciosa y tratado con norfloxacino $200 \mathrm{mg}(1 \mathrm{c} / 12 \mathrm{~h})$ durante 14 días. A las 48 horas de inicio del tratamiento, el paciente acude nuevamente al centro, en calidad de cita urgente, por presentar erupción de lesiones cutáneas tipo micropapular hemorrágico que no desaparecen con la vitropresión de predominio en miembros inferiores pero también en dorso de manos y tronco (Fig. 1). Concomitantemente presenta dolor abdominal difuso y deposiciones líquidas, la última rectorrágica, sin presentar otros signos de sangrado. Se decide realizar pruebas de coagulación INR y hemograma para titulación de plaquetas de forma urgente. Los resultados fueron emitidos por fax en el mismo día, desde el laboratorio central, con normalidad en ambas pruebas (INR entre 2-3, plaquetas 350.000 sin acúmulos). Descartada patología no vascular, se procedería a realizar biopsia de las lesiones bajo la sospecha de que se tratara de una vasculitis con afectación abdominal (púrpura de Schönlein-Henoch). Dados los antecedentes del

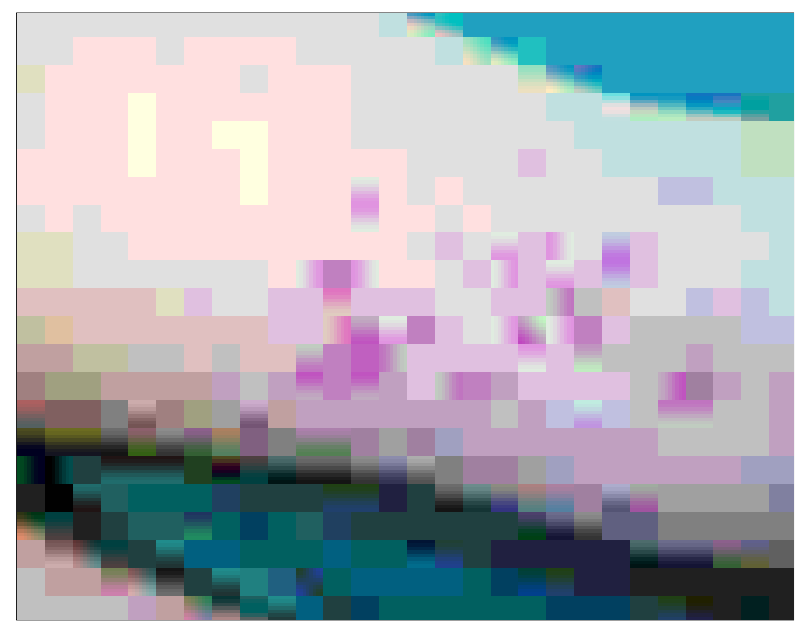

Figura 1 paciente, se decide derivar al servicio de urgencias del hospital de referencia para su estabilización y posterior ingreso en el servicio de medicina interna para su estudio. A su ingreso en planta, se retira tratamiento anticoagulante y antibiótico (norfloxacino), se inicia tratamiento con heparinas de bajo peso molecular, se mantiene 48 horas con sueroterapia y vigilancia de rectorragia y hematuria. Estabilizándose y desapareciendo espontáneamente el dolor abdominal y la diarrea, reiniciando la dieta por vía oral. Se realizaron la batería de pruebas diagnósticas pertinentes y biopsia de la lesión cutánea. Se detectó microhematuria y alteración del perfil hepático, normalizándose ambos parámetros en 10 días. El estudio serológico fue negativo y las lesiones cutáneas regresaron de forma progresiva. Siendo el paciente dado de alta hospitalaria con diagnóstico de: vasculitis leucocitoclástica. Púrpura de Schólein-Henoch, por mecanismo de hipersensibilidad secundario a norfloxacino.

Batería de pruebas complementarias a su ingreso hospitalario:

Hemograma: leucocitos 10.180/ml (fórmula normal); Hbg 13,8 g/dl; plaquetas 336.000.

Coagulación: INR TTPA y TP normales.

Bioquímica: GOT 50,GPT 150 FA 384 y GGT 195.Cr 1,2, Ac. úrico 7,

PCR, FR, Igs, complento, ANAS y ANCA Begativos.

Serología VHA; VHB; VHC; VIH; lúes; Bruce lla y Micoplasma pneumoniae negativos.

$S$. de orina: hematíes $10 / 15$ campo y proteínas 24 $\mathrm{h}$ de $1,32 \mathrm{~g}$.

TAC abdominal: sin alteraciones significativas.

Biopsia cutánea: plexo vascular superficial y profundo con intenso infiltrado inflamatorio con predominio de monocitos, con afectación vascular y presencia de eosinófilos e imagen de vasculitis leucocitoclástica con inmunofluorescencia negativa.

El término de "vasculitis leucocitoclástica" engloba un grupo heterogéneo de síndromes anátomo-clínicos que tienen en común una reacción de hipersensibilidad a diversos estímulos antigénicos y afectan a vasos pequeños preferentemente vénulas. Los agentes inmunorreactivos endógenos o exógenos alteran la pared vascular, aumentan su permeabilidad y facilitan el depósito de inmunocomplejos (Tabla I).

Clínicamente las lesiones cutáneas son las más frecuentes con dos tipos predominantes: púrpura palpable o lesiones urticariformes en distinto estadio evolutivo, de distribución en miembros inferiores, respetando generalmente manos, cara y tronco. Las lesiones uriticariformes son más específicas de la enfermedad del suero o vasculitis hipo-complementémica. Un $40 \%$ tiene sintomatología articular $\mathrm{y}$, en un tercio de los casos, afectación renal con microhematuria pero infrecuentemente se compromete la función renal. 
Tabla I

CLASIFICACIÓN ETIOLÓGICA DE LA PÚRPURA

No palpable, no vascular

Por disminución del número de plaquetas (trombopénicas)

Por alteración de la función plaquetaria (trombopáticas)

Por alteraciones de la coagulación

Palpable vascular 0 angiopática

Vasculitis por hipersensibilidad asociada a agentes precipitantes: vasculitis leucocitoclástica

Infecciosa (bacterias, virus, parásitos)

Medicamentos (penicilinas, tetraciclinas, sulfamidas, eritromicina, griseofulmina, AINEs, tiazidas, propiltiouracilo, yoduros, penicilamina, fenotiacinas, quinidina)

Asociada a desórdenes crónico persistentes:

Colagenosis (LES. A.R. S. de Sjoegren)

Enfermedad inflamatoria intestinal (colitis ulcerosa, enfermedad de Cröhn)

Crioglobulinemia mixta

Púrpura hipergammaglobulinémica de Waldenstrom

Asociada a neoplasias:

Procesos linfoproliferativos

Carcinomas

Idiopáticas

Dentro de estas vasculitis se consideran cuatro grupos especiales:

1. Enfermedad del suero: fiebre, erupción cutánea, artralgias, linfadenopatía y albuminuria. El tiempo necesario para la sensibilización primaria es de 1 a 3 semanas. Analíticamente llama la atención la disminución de niveles séricos de $\mathrm{C} 3$ y $\mathrm{C} 4$ e inmunofluorescencia directa sobre piel positiva.

2. Enfermedad de Shönlein-Henoch: más frecuente en la infancia, aunque puede presentarse en adultos a cualquier edad. Clínicamente se caracteriza por lesiones cutáneas purpúricas, compromiso articular, dolor abdominal cólico y hemorragia gastrointestinal y afectación renal (micro-macrohematuria). La biopsia cutánea muestra la presencia de Ig A en la pared vascular.

3. Crioglobulinemia mixta esencial: púrpura en miembros inferiores, astenia, afectación articular y posible compromiso renal con crioglutininas circulantes.

4. Vasculitis por hipersensibilidad asociada a enfermedades sistémicas: artritis reumatoide, lupus sistémico o de naturaleza tumoral como la leuce- mia linfoide crónica, la enfermedad de Hodgkin y mieloma.

El diagnóstico se confirma con la biopsia, pues no hay ninguna prueba de laboratorio común a todas las entidades.

El tratamiento suele ser sólo sintomático pues la mayoría son procesos autolimitados y benignos. Hay que buscar el agente etiológico en cuestión y proceder a su eliminación. Si es un microorganismo plantear tratamiento antibiótico, si se asocia a una enfermedad subyacente habrá que abordar ésta y sólo cuando existe disfunción orgánica progresiva como la insuficiencia renal en la púrpura de Shönlein-Henoch se debe administrar tratamiento corticoideo con prednisona a dosis de $1 \mathrm{mg} / \mathrm{kg} /$ día. Sólo en casos refractarios a glucocorticoides con disfunción orgánica irreversible estarían indicados los agentes citotóxicos tipo ciclofosfamida.

Es interesante el abordaje inicial de la lesión en Atención Primaria siguiendo un algoritmo decisional sencillo (Fig. 1) que nos acerque a su posible etiología.

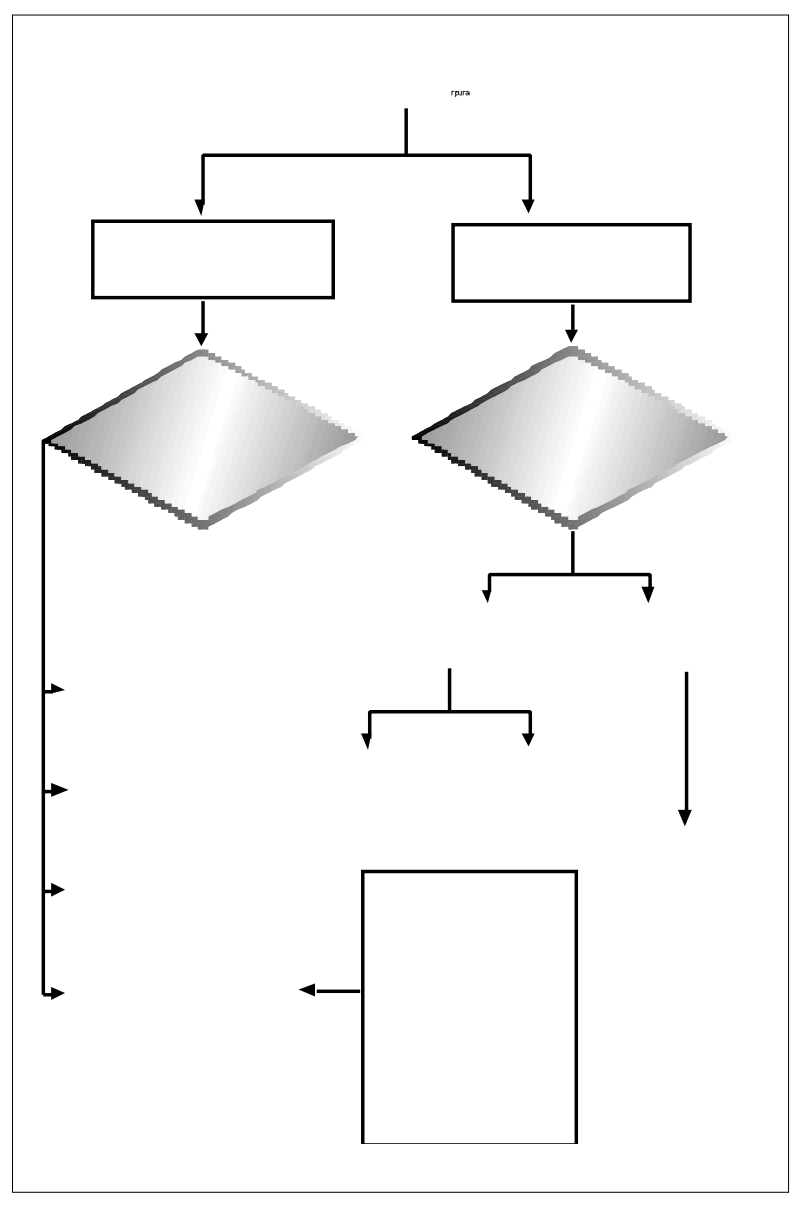

Figura 2

Algoritmo diagnóstico de la púrpura. 


\section{DISCUSIÓN}

La petición de un hemograma, pruebas de cogulación y tener a nuestro alcance la posibilidad de realizar una biopsia (con punch), así como una buena organización con el servicio de anatomía patológica del hospital de referencia, bastará para la presunción diagnóstica (Fig. 1). La carencia de estos medios diagnósticos, impediría el seguimiento en Atención Primaria con la derivación al servicio de dermatología para realizar biopsia.

Como hemos podido comprobar en nuestro caso clínico son tres los factores ${ }^{2}$ que podrían desencadenar una lesión purpúrica: el tratamiento con anticoagulantes (orales), la orquitis como infección intercurrente y la administración de norfloxacino.

El tratamiento anticoagulante con acenocumarol $^{1}$, podría favorecer la aparición de lesiones de aspecto purpúrico no palpable, por alteración en las pruebas de coagulación (INR <2) y sangrado activo a nivel visceral y mucosas. La presencia de lesión purpúrica micropapular agrupadas, palpable ${ }^{4}$, así como la posibilidad de obtener una titulación de INR en menos de 24 h mediante fax desde el laboratorio central, con normalización del INR, descartan esta etiología.

La probable infección por bacterias gram negativas secundaria a la orquitis podría desencadenar, por mecanismos de hipersensibilidad ${ }^{5}$, una vasculitis leucocitoclástica con afectación cutánea y visceral con clínica de púrpura palpable y dolor abdominal con afectación renal, intestinal tipo Shönlein Henoch $^{5-7}$ que podría ser compatible con este cuadro clínico. La presencia de rectorragia hace imposible el seguimiento del paciente en nuestra consulta de Atención Primaria siendo imprescindible su estabilización a nivel hospitalario. La biopsia de la lesión cutánea ${ }^{2,3}$ es imprescindible para confirmar el diagnóstico de vasculitis; la anatomía patológica con predominio de células monocíticas frente a neutrófilos así como el estudio serológico negativo de las posibles causas infecciosas más prevalentes hacen desestimar el origen infeccioso.

La regresión de lesiones cutáneas así como la desaparición de la sintomatología digestiva y la normalización del perfil hepático y la microhematuria tras la retirada del fármaco (norfloxacino) implica directamente a éste como posible desencadenante del fenómeno de hipersensibilidad. Realizando una revisión de casos en la literatura médica (MEDLINE) sobre vasculitis y fármacos (efectos secundarios) en el último año sólo hay descrito un caso de quinolonas con ciprofloxacino ${ }^{8}$. Este caso podría cumplir claramente los criterios de vasculitis por hipersensibilizacion a otra quinolona (norfloxacino).

\section{CORRESPONDENCIA:}

Belén Aguado Martínez

Centro de Salud San Fernando

C/ Azorín, 3

28935 Móstoles

Madrid

Fax: 91/6175513

\section{Bibliografía}

1. Domingo Claros A. Problemas hematológicos. En: Martín Zurro A, Cano Pérez JF. Atención Primaria: Conceptos, organización y práctica clínica. $4^{\mathrm{a}}$ ed. Madrid: Harcourt Brace de España S.A. 1999. p. 1345-71.

2. Calabrese LH, Michel BA, Bloch DA, Arend WP, Fauci AS American College of Rheumatology 1990. Criteria for the classification of Vasculitis. Arthritis Rheum 1990; 33: 1065136.

3. Sánchez Rodríguez A, De Portugal Álvarez J. Vasculitis. En: Díaz Rubio M, Espinos D. Tratado de Medicina Interna. $1^{\text {a }}$ ed. Madrid: Editorial Médica Panamericana, 1996. p. 2830-8.

4. García Porrua C, Llorca J, González Louzano C, González Gay MA. Hypersensitivity vasculitis in adults: a benign disease usually limited to skin. Clin Exp Rheumatol 2001; 19: 85-8.

5. Rostoker G, Slönlein Henoch purpura in children and adults: diagnosis pathophysiology and management. Bio Drugs 2001; 15: 99-138

6. Novak J, Marki Zay J, Csikiz Sebesi J, Takats A, Sipka S. Shönlein Henoch purpura in adulthood (gastrointestinal manifestation and endoscopy). Z Gastroenterol 2001; 39: 775-82.

7. Lippl F, Huber W, Werner M, Nekarda H, Berger H, Weigert NS. Shönlein Henoch purpura. Endoscopy 2001; 33: 811-3.

8. Pons R, Escutia B. Ciprofloxacin-induced vasculitis with cutaneous and renal involvement. Nefrologic 2001; 21: 209-12. 